\title{
APPLICABILITY OF THE CARBON-DATING METHOD OF ANALYSIS TO SOIL HUMUS STUDIES
}

\author{
C. A. Campbell, E. A. Paul, D. A. Rennie, and K. J. McCallum \\ University of Saskatchewan ${ }^{1}$
}

The organic fraction of soil is known to be composed of the soil biomass, partially decomposed plant and animal residues, and the materials commonly referred to as humic substances. Knowledge of the persistence of these fractions in soil is vital to the understanding of their contribution to soil fertility and soil genesis. Much information concerning the biochemistry of the humus materials also could be obtained through a knowledge of the mean residence times of the various organic fractions.

The nature of the organic compounds and of the organo-mineral bonds varies from soil to soil; consequently, the relative stability of the organic matter of different soils should also vary $(8,16)$. Tyurin investigated the nature of the humus of the main soil types of the U.S.S.R. He found that the chernozemic humic acids were relatively complex with a preponderance of calcium humates, which were said to be very stable. In contrast, the humus of podzolic soils was associated primarily with nonsilicate forms of iron and aluminum and consisted of relatively simple organic structures. These were thought to be relatively mobile and unstable $(7,17)$.

The availability of the carbon-dating technique has made it feasible to determine the mean residence time of soil humic fractions $(2,4,11)$. Thus, the general postulations concerning the relative stability of the soil humic components can now be tested. Campbell and Paul (3) discussed the factors which affect the accuracy of the carbon-dating method of analysis when applied to soils. Isotopic fractionation of the carbon isotopes results in a fairly constant correction to each apparent mean residence time (m.r.t.). No large error was observed to result from the increase of nuclear-bomb-produced C14 in the atmosphere; other errors were relatively small. The present study was undertaken to utilize the natural C14 activity of the carbon in the various organic fractions to provide an accurate comparison of the relative stability of a number of soil organic matter fractions.

\section{METHODS}

\section{Fractionation of soil organic matter}

The Melfort (chernozemic black) and Waitville (podzolic grey-wooded) soils used in this study were described previously (11). The "mobile" humates were extracted from both soils, using $0.5 \mathrm{~N} \mathrm{NaOH}$ without an acid pretreatment. The residual

\footnotetext{
${ }^{1}$ Contribution No. R 11, Saskatchewan Institute of Pedology, University of Saskatchewan, Saskatoon, Saskatchewan, Canada. Data taken from the senior author's Ph.D. thesis. The senior author is presently Research Officer, Canada Department of Agriculture, Swift Current, Saskatchewan.
} 
carbon after alkali extraction was called Humin I. The Humic Acids I and Fulvic Acids I were then separated by precipitation of the humic acids at $\mathrm{pH} 2$. The "total" humic acids were extracted from both soils (fig. 1) and Humin II and Humic Acids II of the Melfort soil were further hydrolyzed with $6 \mathrm{~N} \mathrm{HCl}$ (1). The commonly accepted names of each fraction are indicated on the schematic fractionation diagram.

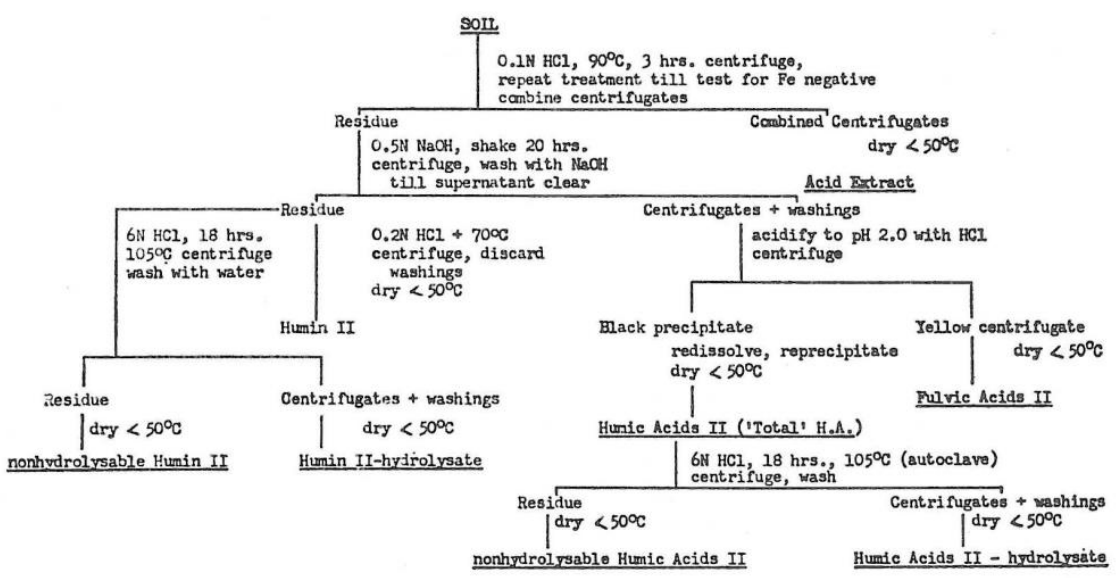

Fig. 1. Fractionation scheme of Melfort and Waitville soils, showing "Total" Humic Acids, and hydrolysis fractions of Melfort soil.

To characterize the humic substances stabilized by calcium, the residue after $\mathrm{NaOH}$ treatment (Humin I in the "mobile" fractionation) was acid-treated in a manner identical to that for the "total" soil shown in figure 1. The residue, after acid treatment, was extracted with $0.5 \mathrm{~N} \mathrm{NaOH}$, the $\mathrm{pH}$ of the extract was adjusted to 2.0, and the humates were separated by centrifugation. The remaining centrifugate was combined with the acid extract from the treatment of Humin I, and this fraction was called the "Calcium Fulvates."

\section{Carbon-dating}

All soils and most fractions were carbon-dated and the apparent mean residence times corrected for $\mathrm{C} 14$ discrimination (3).

\section{Elemental analysis}

Total carbon was determined on the soils and fractions by the dry-combustion method (13). Inorganic carbon was found to be negligible in both soils.

Optical analysis

Various humate fractions were prepared at a concentration of $0.01 \mathrm{~g}$. carbon/liter by dissolving appropriate amounts in $0.02 \mathrm{~N} \mathrm{NaHCO}$, and adjusting the $\mathrm{pH}$ (7) to 7.0. The optical densities (extinction coefficients) of these solutions were determined 
between wavelengths 350 and $650 \mathrm{m \mu}$. The $\mathrm{E}_{4} / \mathrm{E}_{6}$ ratios were calculated, using the $465 \mathrm{~m} \mu$ and $650 \mathrm{~m} \mu$ extinction coefficients.

\section{RESULTS}

The direct treatment of a soil with $0.5 \mathrm{~N} \mathrm{NaOH}$ without acid pretreatment yielded the "mobile" humates. The percentage distribution of carbon among the three fractions (table 1) was almost identical for the Melfort (chernozemic black 5.6 per cent organic C) and Waitville soils (podzolic grey-wooded 1.96 per cent organic C). The soils had a marked difference in their overall mean residence time (m.r.t.), but they showed a similarity in the pattern of the relative stability of their fractions. For example, in each soil the humin fraction had a much greater m.r.t. than the "mobile" humic acids fraction, the difference being about 350 years for the Melfort soil and 250 years for the Waitville. The very small difference between the m.r.t. of the "mobile" humic acids fraction and the fulvic acids fraction of the Waitville is probably due to the fact that the m.r.t. of the "mobile" humic acids is already very small (85 years).

The results (table 1) also show that the turnover of organic carbon in all three fractions of the Waitville soil is more rapid than that of even the most labile fraction of the Melfort soil, since the youngest fraction of the Melfort has a greater m.r.t. than the most stable fraction of the Waitville.

\section{TABLE 1}

Mean residence times of fractions extracted from Melfort and Waitville soils without acid pretreatment

\begin{tabular}{|l|r|r|r|r|}
\hline \multirow{2}{*}{ Fraction } & \multicolumn{2}{|c|}{ Melfort Soil } & \multicolumn{2}{c|}{ Waitville Soil } \\
\cline { 2 - 5 } & $\begin{array}{c}\text { \% of } \\
\text { total } \\
\text { carbon }\end{array}$ & $\begin{array}{c}\text { m.r.t. } \\
\text { (yr.) }\end{array}$ & $\begin{array}{c}\text { \% of } \\
\text { total } \\
\text { carbon }\end{array}$ & $\begin{array}{c}\text { m.r.t. } \\
\text { (yr.) }\end{array}$ \\
\hline Humin I & 58 & $1135 \pm 50$ & 56 & $335 \pm 50$ \\
\hline $\begin{array}{l}\text { Humic Acids I } \\
\text { ("mobile") }\end{array}$ & 269 & $785 \pm 50$ & 25 & $85 \pm 45$ \\
\hline Fulvic Acids I & 18 & $555 \pm 45$ & 17 & $50 ? *$ \\
\hline Unfractionated Soil & 100 & $870 \pm 580$ & 100 & $250 \pm 60$ \\
\hline
\end{tabular}

- This value was calculated from the measured per cent of total $\mathrm{C}$ for each fraction and the radiocarbon activity of each fraction other than fulvic Acids I.

The various fractions of the soils underwent quantitative changes as a result of the acid pretreatment (table 2), which removed the exchangeable calcium and some of the sesquioxides. In both soils, the humin and fulvic acids fractions decreased in total carbon while the humic acids fraction increased. The acid pretreatment resulted in a new fraction, the acid extract. The relative order of stability of the organic matter in the fractions of the Waitville soil for the "total" fractionation was the same as that for the "mobile" fractionation. This, however, was not so for the 
Melfort soil where, after acid pretreatment, the humic acids fractions became the oldest fraction.

TABLE 2

Mean residence times of fractions isolated from Melfort and Waitville soils after acid pretreatment

\begin{tabular}{|l|r|r|r|c|}
\hline \multirow{2}{*}{\multicolumn{1}{|c|}{ Fraction }} & \multicolumn{2}{|c|}{ Melfort Soil } & \multicolumn{2}{c|}{ Waitville Soil } \\
\cline { 2 - 5 } & $\begin{array}{c}\text { \% of } \\
\text { total } \\
\text { carbon }\end{array}$ & $\begin{array}{c}\text { m.r.t. } \\
\text { (yr.) }\end{array}$ & $\begin{array}{c}\text { \% of } \\
\text { total } \\
\text { carbon }\end{array}$ & $\begin{array}{c}\text { m.r.t. } \\
\text { (yr.) }\end{array}$ \\
\hline Humin II & 30.8 & $1140 \pm 50$ & 32.2 & $485 \pm 70$ \\
\hline $\begin{array}{l}\text { Humic Acids II } \\
\text { ("total") }\end{array}$ & 40.3 & $1235 \pm 60$ & 37.3 & $195 \pm 50$ \\
\hline Fulvic Acids II & 14.8 & $495 \pm 60$ & 13.2 & -- \\
\hline Acid Extract & 13.7 & $325 \pm 60$ & 16.1 & -- \\
\hline $\begin{array}{l}\text { Acid Extract Fulvic + } \\
\text { Acids II }\end{array}$ & 28.5 & $470 \pm 60$ & 29.3 & 0 \\
\hline Unfractionated Soil & 100 & $870 \pm 50$ & 100 & $250 \pm 60$ \\
\hline
\end{tabular}

The increase in m.r.t. of the humic acids fraction separated after acid pretreatment implies that the "calcium" humates (that is, the extra humic acids solubilized as a result of the acid pretreatment) must of necessity be fairly old. To verify this observation, Humin I of the Melfort soil was acid-treated in a manner identical to that for the total soil, as shown in figure 1, and then extracted with $0.5 \mathrm{~N} \mathrm{NaOH}$. The $\mathrm{NaOH}$ extract thus contained humates and fulvates which had previously been stabilized by calcium. The "calcium" humates (1410 years) were found (table 3 ) to be much older than the "mobile" humic acids (785 years).

TABLE 3

"Calcium" humates and fulvates isolated from Humin I of the Melfort soil by means of acid treatment followed by $0.5 \mathrm{~N} \mathrm{NaOH}$ extraction

\begin{tabular}{|l|r|r|}
\hline \multicolumn{1}{|c|}{ Fraction } & $\begin{array}{c}\text { \% of total } \\
\text { carbon }\end{array}$ & m.r.t. (yr.) \\
\hline "Calcium" humates & 21.0 & $1410 \pm 95$ \\
\hline "Calcium" fulvates & 12.0 & -- \\
\hline Humin III & 26.0 & -- \\
\hline Total & 59.0 & -- \\
\hline Humin I & 58.0 & $1135 \pm 50$ \\
\hline
\end{tabular}

The use of radioactively labeled organic materials has indicated that the freshly incorporated organic residues first enter the hydrolyzable portion of the humus (5, $12,14,15)$. This fraction, therefore, is said to represent "nutritive" or "active" 
humus (that is, the fraction of the humus which readily supplies such nutrients as nitrogen, phosphorus, sulfur, etc.). If this is so, then the hydrolysate should be one of the "youngest" fractions of the soil humus. Hydrolysis of the Humic Acids II and Humin II fraction of the Melfort soil indicated how very resistant the major portions of these fractions are. The humin and humic acids hydrolysates each made up only 7 per cent of the total organic carbon (table 4). The humic acids hydrolysate was composed almost entirely of modern carbon, as indicated by its very low m.r.t. In contrast, the nonhydrolyzable residue was extremely stable. This suggests that a very small fraction of the organic matter in soil turns over at a fairly rapid rate and supplies various nutrients to plants, whereas the major portion is more or less inert and is probably more important in such processes as cation exchange, formation of stable aggregates, and water adsorption.

The humin fraction upon hydrolysis-produced fractions which had m.r.t.'s very much like that of the fulvic acids and "total" humic acids. The m.r.t. of the humin hydrolysate, like that of the fulvic acids, was approximately 500 years, while that of the nonhydrolyzable humin and of the "total" humic acids were each about 1230 years.

TABLE 4

Mean residence time (m.r.t.) and distribution of carbon among the fractions resulting from the hydrolysis of Humic Acids II and Humin II of the Melfort soil

\begin{tabular}{|l|r|r|}
\hline \multicolumn{1}{|c|}{ Fraction } & $\begin{array}{c}\text { \% of total } \\
\text { carbon }\end{array}$ & m.r.t. (yr.) \\
\hline Humin II & 30.8 & 114050 \\
\hline Nonhydrolyzable Humin II & 23.5 & 123060 \\
\hline Humin II - hydrosylate & 7.3 & 46550 \\
\hline Humic Acids II ("total") & 40.3 & 123560 \\
\hline Nonhydrolyzable Humic Acids II & 33.2 & 140060 \\
\hline Humic Acids II - hydrolyzsate & 7.1 & 2550 \\
\hline
\end{tabular}

To augment the carbon-dating characterization of the humic fractions, optical analyses were conducted on some of the fractions of the Melfort and Waitville soils. The light absorption spectra of the humic materials decreased gradually and smoothly from the near ultraviolet towards the near infrared region of the spectrum (figs. 2 and 3). The lack of distinct shoulders or peaks in the curves is probably due to the poorly defined, heterogenous nature of humic substances. The optical-density values of the humate solutions of the Waitville soil (fig. 2) increased in the order: Humic Acids-Humic Acids II—nonhydrolyzed Humic Acids I-nonhydrolyzed Humic Acids II. The order was similar for the same fractions of the Melfort soil (fig. 3), except that the latter two fractions gave almost identical curves. The curve for the "calcium" humates of the Melfort soil differed from the other curves. Although the light absorption of this fraction was greater above $450 \mathrm{m \mu}$ than that of the "total" humic acids and the "mobile" humic acids, the absorption between 


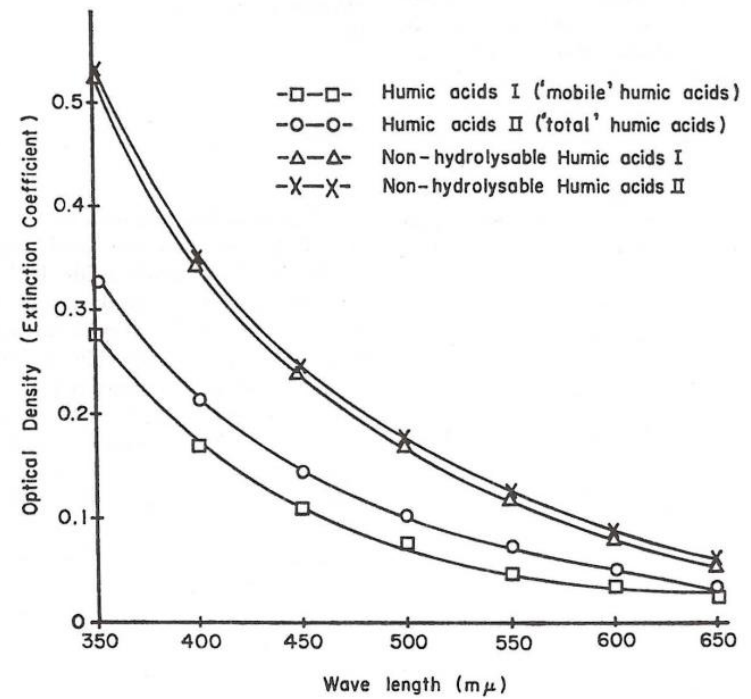

Fig. 2. Optical curves of Waitville humic acid fractions.

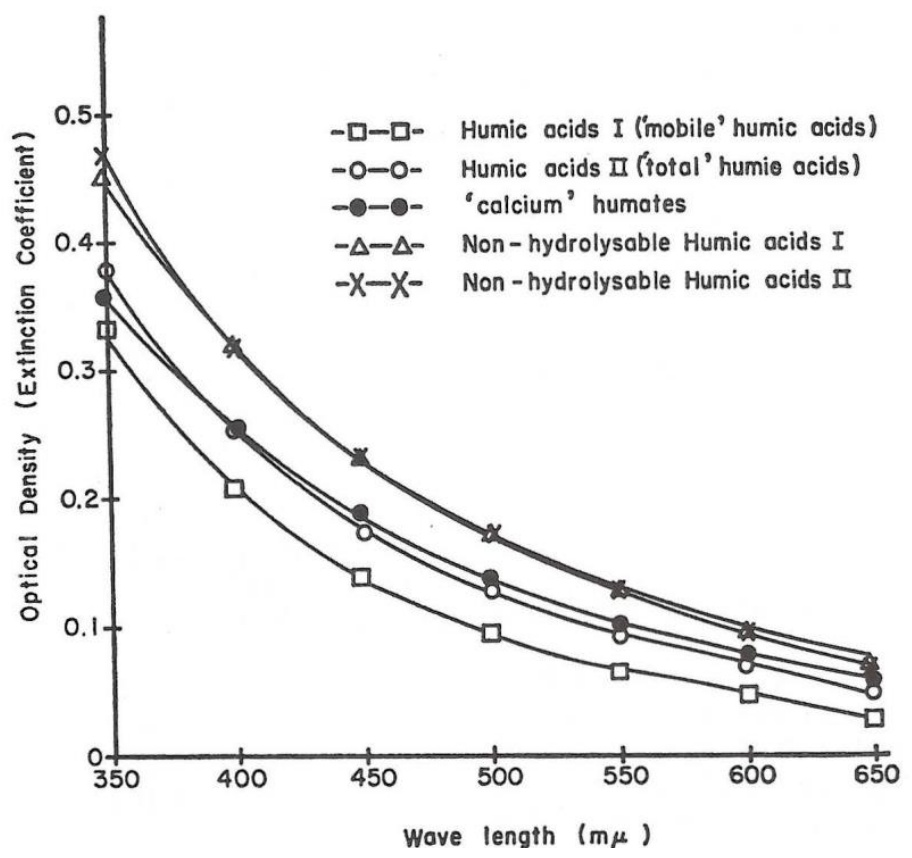

Fig. 3. Optical curves of Melfort humic acid fractions.

wavelengths 450 and $350 m \mu$ was intermediate to that of the "total" humic acids and the "mobile" humic acids.

The relative light absorption at a number of specific wavelengths often reveals more information than the general curves. The $E_{4} / E_{6}$ ratio, which refers to the light absorbance at $465 m \mu$ in relation to that at $660 m \mu$, has been used as a measure of the degree of condensation of the aromatic nucleus of the humate materials (7). The 
ratio decreases with shortening of carbon chains which link the aromatic rings. The "mobile" fraction had the widest $E_{4} / E_{6}$ ratio; the "calcium" humates the lowest ratio (table 5). Since Humic Acids II ("total" humic acids) is essentially a composite of the "mobile" humic acids and "calcium" humates, it was expected that its $E_{4} / E_{6}$ ratio would be intermediate to those of the latter two fractions. This was found to be so for the Melfort soil.

TABLE 5

$E_{465} / E_{650}$ ratios of humic acid fractions of Melfor and Waitville soils

\begin{tabular}{l|c|c}
\hline \multirow{2}{*}{\multicolumn{1}{c|}{ Fraction }} & Melfort Soil & Waitville Soil \\
\cline { 2 - 3 } & $\mathrm{E}_{465} / \mathrm{E}_{650}$ & $\mathrm{E}_{465} / \mathrm{E}_{650}$ \\
\hline Humic Acids I ("mobile") & 1.28 & 4.26 \\
Humic Acids II ("total") & 3.14 & 3.77 \\
"Calcium" humates & 3.00 & N.D.* \\
Nonhydrolyzable Humic Acids I & 3.02 & 3.69 \\
Nonhydrolyzable Humic Acids II & 3.02 & 3.60 \\
\hline
\end{tabular}

$*$ N.D. $=$ not determined.

Upon hydrolysis of the humic acids there is a tendency to solubilize the constituents, such as the carbohydrates and the amino-nitrogen-containing compounds, and leave the more complex aromatic components behind (10). The nonhydrolyzable humic fractions exhibited a relatively more condensed "aromatic nucleus" than their unhydrolyzed sources, as evidenced by their $\mathrm{E}_{465} / \mathrm{E}_{650}$ ratios.

An inverse relationship (fig. 4) was found to exist between the $\mathrm{E}_{465} / \mathrm{E}_{650}$ ratios and the mean residence times of the various humic fractions of the Melfort soil. The fractions with the lowest mean residence times had the widest ratio. Comparisons between soils, however, cannot be made at this stage since, although some of the fractions of both the chernozemic and podzolic soils had somewhat similar $\mathrm{E}_{465} / \mathrm{E}_{650}$ ratios, their m.r.t.s varied widely.

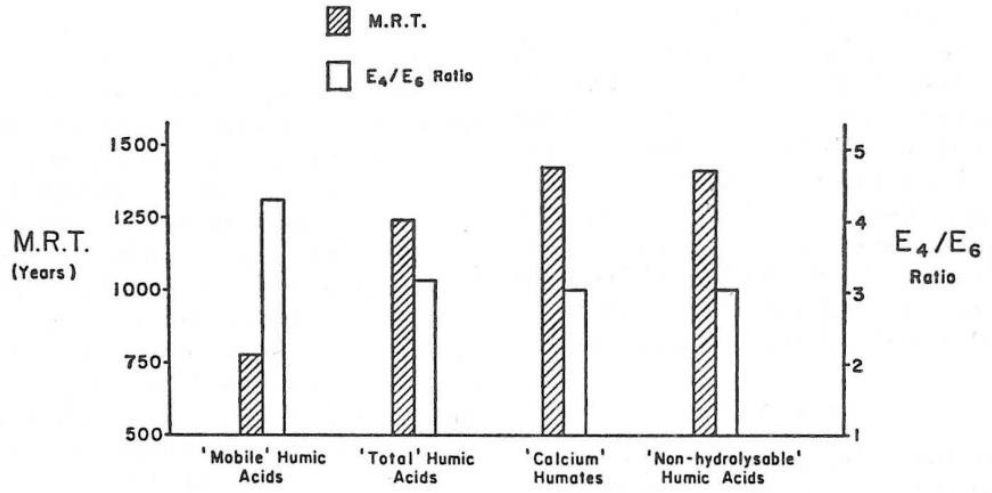

Fig. 4. Relationship between m.r.t. and $\mathrm{E}_{4} / \mathrm{E}_{6}$ ratio of humates of the Melfort soil. 


\section{DISCUSSION}

The carbon-dating method, when supported by other chemical methods of analysis, shows considerable promise as means of characterizing the organic matter fraction of soils. The utilization of standard techniques, such as $\mathrm{NaOH}$ extraction followed by precipitation at $\mathrm{pH} 2$, results in the commonly recognized fractions (10). It is known that the humates removed by these techniques are a mixture of materials. The difficulty with which they are separated electrophoretically (6), the reproducibility of fractionation techniques, and the fairly small range in molecular weights $^{2}$ ca. 5000 to 100000 indicates that these materials may have a common structure. The acid-hydrolyzable fraction, which has a low m.r.t. and is primarily composed of such materials as amino acids and amino sugars, cannot be separated from the high m.r.t.-aromatic portions without such drastic treatment as hydrolysis. The amino fraction must, therefore, be closely associated with the aromatic materials, possibly in the form of side chains.

It was noted earlier that although the Waitville soil is classified as a podzolic greywooded soil and the Melfort as a chernozemic black soil, the distribution of the carbon between the humic fractions was very similar for both soils. Both soils had a humic acids/fulvic acids ratio $>1$ (fulvic acids in this case includes both Fulvic Acids II + acid extract). This, according to the Russian literature (7), would place both soils in the chernozemic great group. In contrast, the m.r.t. of the organic matter of these two soils differed markedly (the Melfort was about 600 years older than the Waitville). The $\mathrm{E}_{4} / \mathrm{E}_{6}$ ratios of the Melfort and Waitville humates also indicated that these soils were from different great soil groups (7). A comparison of the results obtained with and without acid pretreatment suggests that, in the Waitville soil, the clay plays a greater role in stabilizing humic carbon than do the metallicions; in the Melfort soil; however, the metallic ions play as important a role in stabilizing humic carbon as does the clay. This observation substantiates views expressed in the literature (7), where it is suggested that the Chernozems, calcium, and clays play an equally important role in stabilizing humus, whereas in dernopodzols (grey-wooded) the calcium, although present, is more soluble and plays a lesser role in this respect.

Optical measurements such as $\mathrm{E}_{4} / \mathrm{E}_{6}$ ratio have not been extensively utilized in North American research on humic materials. The observed inverse relationship between the $\mathrm{E}_{4} / \mathrm{E}_{6}$ ratio and the m.r.t. of the materials indicates that this optical measurement might be correlated with the ability to resist decomposition in soil.

The component with the more condensed aromatic nucleus should be more stable than the component which has a more aliphatic type of structure. Several organisms, however, are known to attack and degrade aromatic rings. For example, Mathur and Paul recently isolated a fungus which degrades up to 35 per cent of the "mobile" humic acids (9). The nature of the aromatic nucleus of the humates is not the only

\footnotetext{
${ }^{2}$ S. Mathur, Ph.D. thesis, University of Saskatchewan, 1966.
} 
factor controlling their relative stability in soils. Such factors as amount and type of clay, sesquioxides, and cations, and the physical accessibility of the humates to the wide range of enzymes required for their degradation also play a very important role in their ease of decomposition.

\section{SUMMARY}

Humic fractions from the Ap horizon of chernozemic black and podzolic greywooded soils were characterized by carbon-dating and chemical analyses.

The natural C14 activity of the organic matter fractions suggested that the humin was much more stable than the "mobile" humic acids and the latter more resistant to decomposition than the fulvic acids. Humic fractions of the podzolic grey-wooded soil were less stable than their chernozemic counterparts. Fractions of the chernozemic humic acids ranged from the very stable calcium humates (1400 years) to the labile humic acid hydrolysates (25 years); the mobile humic acids were intermediate (780 years).

The fractions also differed in their optical properties. There were indications that an inverse relationship exists between the relative light absorption at 465 and $650 \mathrm{m \mu}$ and the stability of soil humus.

Carbon-dating data, augmented by optical and chemical data, were used to demonstrate the relative role of clay and sesquioxides in the stabilization of humates. In the chernozemic soils the metallicions and clays play an equally important role in the stabilization of the humic materials. In the podzolic soil the oldest humic fraction was associated with the clays. It was concluded that the carbon-dating method supported by other chemical methods of analysis is a useful research procedure in soil organic matter investigations.

\section{REFERENCES}

(1) Bremner, J. M. 1955. Studies on soil humic acids: I. J. Agr. Sci. 46: 247-256.

(2) Broecker, W. S., and Olson, E. A. 1960. Radiocarbon from nuclear tests: II. Science 132: 712-718.

(3) Campbell, C. A., et al. 1967. Factors affecting the accuracy of the carbon-dating method in soil humus studies. Soil Sci. 104: 81-35.

(4) Felgenhauer, F., Fink, J., and De Vries, H. 1959. Studien zur absoluten und relativen chronologie der fossilen boden in Osterreich: I. Archaeologia Austrica, 25: 418-421.

(5) Jansson, S. K. 1963. Balance sheet and residual effects of fertilizer nitrogen in a six-year study of N-15. Soil Sci. 95: 31-37.

(6) Kaurichev, L. S., Fedorov, Y. A., and Shnabel, I. A. 1960. Separation of humic acids by the continuous electrophoresis method. Soviet Soil Sci. 12: 1050-1053.

(7) Kononova, M. M. 1961. "Soil Organic Matter." Pergamon Press, New York.

(8) Kyuma, K. 1959. Recent investigations on soil humus in Japan. Soviet Soil Sci. 11: 901-907. 
(9) Mathur, S. P., and Paul, E. A. 1967. Microbial utilization of soil humic acids. Can. J. Microbiol. 13: 573-580.

(10) Mortensen, J. L., and Himes, F. L. 1964. Soil organic matter. (In "Chemistry of the Soil," 2nd ed., pp. 206-241, F. E. Bear (ed.), Reinhold Publishing Company, New York.)

(11) Paul, E. A., et al. 1964. Investigations of the dynamics of soil humus, utilizing carbon-dating techniques. Trans. Intern. Congr. Soil Sci. 8th Congr. Bucharest (1964), Comm. II. In press.

(12) Sorensen, H. 1963. Studies on the decomposition of $\mathrm{C}^{14}$-labeled barley straw in soil. Soil Sci. 95: 45-51.

(13) St. Arnaud, R. J. 1956. "Manual of Laboratory Methods.” Dept. of Soil Sci., Univ. of Saskatchewan.

(14) Stewart, B. A., Johnson, D. D., and Porter, L. K. 1963. The availability of fertilizer nitrogen immobilized during decomposition of straw. Soil Sci. Soc. Am. Proc. 27: 656-659.

(15) Stewart, B. A., Porter, L. K., and Johnson, D. D. 1963 The immobilization and mineralization of nitrogen in several or- ganic fractions of soil. Soil Sci. Soc. Am. Proc. 27: 302-304.

(16) Swaby, R. J., and Ladd, J. N. 1962. Chemical nature, microbial resistance, and origin of soil humus. Trans. Intern. Soils Conference, New Zealand.

(17) Tyurin, I. V. 1953. Methods of analysis for the comparative study of soil humus composition. Chem. Abstr. 47: 5597. 